\title{
Latex glove sensitivity amongst diagnostic imaging healthcare personnel: a study in Southeastern Nigeria.
}

\author{
Charles U. Eze ${ }^{1}{ }^{*}{ }^{1}$ Augustine O. Okaro ${ }^{1}$ and Ivor C. Nwobi ${ }^{2}$ \\ 1.Department of Medical Radiography and Radiological Sciences Faculty of Health Sciences and \\ Technology, University of Nigeria, Enugu Campus, Enugu State, Nigeria. 2. Department of \\ Radiography, College of Medical Sciences, University of Maiduguri, Maiduguri, Borno State,
}

Nigeria.

Address for Correspondence: C.U. EZE; Department of Medical Radiography and Radiological Sciences, Faculty of Health Sciences and Technology, University of Nigeria, Enugu Campus, Enugu State, Nigeria.

ezecharlesu@yahoo.com

\section{SUMMARY}

The paper reports a cross-sectional study to determine the prevalence and type of symptoms, causal agents and awareness of latex glove reactions amongst four professional groups. The study was done at diagnostic imaging departments within ten major hospitals in Southeastern Nigeria. Radiologists/resident radiologists, radiographers, radiology nurses and darkroom technicians who were occupationally exposed to latex gloves were investigated between June and September 2006 to determine the level of latex hypersensitivity. The results show that prevalence is similar to that demonstrated elsewhere with $12.4 \%$ of individuals expressing latex associated symptoms. Symptoms included itching and redness of hands, dry cracked skin, soreness of eyes, and upper respiratory tract complaints. There are strong relationships between number of gloves used per day, duration of glove use and expression of symptoms. About $62.8 \%(n=76)$ of the respondents had previous knowledge of hypersensitivity reaction to latex gloves prior to this investigation. The paper concludes that latex hypersensitivity is a real problem amongst diagnostic imaging healthcare personnel in our locality. This preliminary work, therefore, provides the basis of a much larger controlled study in the future.

[Afr J Health Sci. 2008; 15:28-33]

\section{Introduction}

Natural rubber latex is used in the production of a number of healthcare devices including wound drains, barium enema catheters, stethoscopes, and gloves [1,2]. The use of universal precautions to protect healthcare workers from Hepatitis B and C and Human Immunodeficiency Virus has increased exposure to latex gloves [3]. Gloves are universally considered a necessity to minimize the risk of infection during patient care and surgery. Scientific data has proven that gloves serve as a two-way barrier against the transmission of disease, protecting both the patient and the healthcare worker [4].
The significant increase in glove usage nowadays, undoubtedly, led to some changes by manufacturers of latex gloves. Shorter washing times and shorter shelf times combined with inexperienced manufacturers taking on production to cope with the increased demand, resulted in an increased antigen count in the finished latex glove product [5].

Although much has been published on latex hypersensitivity elsewhere, there is a paucity of data on prevalence levels amongst Nigerian healthcare personnel using latex rubber gloves. The aim of this self reporting study was, therefore, to investigate the level of 
latex hypersensitivity within a group of personnel working in radiology departments in ten major hospitals in Southeastern Nigeria.

\section{Materials and Methods}

The hospitals studied were sampled using a convenient purposive sampling method. Ten major hospitals having full compliment of radiology staff in the five Southeastern states of Nigeria (Abia, Anambra, Ebonyi, Enugu and Imo states) were selected. The hospitals include University of Nigeria Teaching Hospital (UNTH), Enugu; Enugu State University Teaching Hospital (ESUTH), Parklane Enugu; National Orthopeadic Hospital (NOH), Enugu; Nnamdi Azikiwe University Teaching Hospital (NAUTH), Nnewi; Abia State University Teaching Hospital (ABSUTH), Aba; Federal Medical Centre (FMC), Umuahia; Federal Medical Centre (FMC), Abakaliki; Ebonyi State University Teaching Hospital (EBSUTH), Abakaliki; Federal Medical Centre (FMC), Owerri; and Imo State University Teaching Hospital (IMSUTH), Orlu.

Four professional groups studied and their population include radiologists/resident radiologist (40); radiographers (52), radiology nurses (27), and darkroom technicians (34) between June and September, 2006.

A questionnaire was used that had 18 closed and open-ended questions divided into three sections. The first part established the prevalence of symptoms amongst respondents and the type of symptoms experienced. A list of symptoms associated with latex hypersensitivity was drawn up from the literature [6,7]. The second part aimed to establish causal factors associated with expression of symptoms such as previous history of atopism, the type and number of gloves used in a day and the period of time worn. The third part of the questionnaire investigated respondents' awareness of latex hypersensitivity and level of knowledge of prevention strategies.

The questionnaires were distributed to each of the radiologists/residents, radiographers, radiology nurses and darkroom technicians in each hospital surveyed. This ensured that the experiences and opinions of all X-ray personnel who might have an opportunity to come in contact with latex gloves were sought. Prior to the commencement of the study, staff was informed of the study and its aims and confidentiality assured.

A simple descriptive statistics was used to establish the prevalence and awareness levels of hypersensitivity to latex gloves. Correlation coefficient analysis was used to identify parameters that were linked to the expression of latex hypersensitivity.

\section{Results}

One hundred and twenty one questionnaires were returned out of a total of 153 , giving a response rate of $79 \%$ (Tables 1 and 2 ).

Table 1. Population of diagnostic imaging staff in the hospitals surveyed.

\begin{tabular}{|l|l|l|l|l|}
\hline Hospital & $\begin{array}{l}\text { No } \\
\text { Radiologists } \\
\text { /Residents }\end{array}$ & $\begin{array}{l}\text { No of } \\
\text { Radiographers }\end{array}$ & $\begin{array}{l}\text { No of Radiology } \\
\text { Nurses }\end{array}$ & $\begin{array}{l}\text { No } \\
\text { Darkroom } \\
\text { Technicians }\end{array}$ \\
\hline FMC, OWERRI & 2 & 5 & 2 & 4 \\
\hline IMSUTH, ORLU & 4 & 5 & 2 & 3 \\
\hline $\begin{array}{l}\text { FMC, } \\
\text { ABAKALIKI }\end{array}$ & 2 & 4 & 3 & 5 \\
\hline $\begin{array}{l}\text { EBSUTH, } \\
\text { ABAKALIKI }\end{array}$ & 2 & 7 & 5 & 5 \\
\hline $\begin{array}{l}\text { FMC, } \\
\text { UMUAHIA }\end{array}$ & 1 & 5 & 2 & 3 \\
\hline ABSUTH, ABA & 2 & 5 & 2 & 2 \\
\hline NAUTH, NNEWI & 4 & 5 & 2 & 3 \\
\hline UNTH, ENUGU & 20 & 8 & 4 & 4 \\
\hline ESUTH, ENUGU & 2 & 1 & 2 & 2 \\
\hline NOHE, ENUGU & 1 & 7 & 3 & 3 \\
\hline TOTAL & 40 & 52 & 27 & 34 \\
\hline
\end{tabular}


Table 2. Distribution of the respondents who filled and returned their questionnaire

\begin{tabular}{|l|l|l|l|l|}
\hline Hospital & $\begin{array}{l}\text { Radiologists } \\
\text { /Residents }\end{array}$ & Radiographers & Radiology Nurses & $\begin{array}{l}\text { Darkroom } \\
\text { Technicians }\end{array}$ \\
\hline FMC, OWERRI & 2 & 4 & 2 & 3 \\
\hline IMSUTH, ORLU & 4 & 4 & 2 & 3 \\
\hline $\begin{array}{l}\text { FMC, } \\
\text { ABAKALIKI }\end{array}$ & 1 & 4 & 3 & 4 \\
\hline $\begin{array}{l}\text { EBSUTH, } \\
\text { ABAKALIKI }\end{array}$ & 2 & 5 & 3 & 3 \\
\hline $\begin{array}{l}\text { FMC, } \\
\text { UMUAHIA }\end{array}$ & 1 & 4 & 1 & 2 \\
\hline ABSUTH, ABA & 2 & 4 & 1 & 2 \\
\hline NAUTH, NNEWI & 2 & 5 & 2 & 2 \\
\hline UNTH, ENUGU & 13 & 7 & 3 & 4 \\
\hline ESUTH, ENUGU & 1 & 1 & 1 & 2 \\
\hline NOHE, ENUGU & 1 & 7 & 2 & 2 \\
\hline TOTAL & 29 & 45 & 20 & 27 \\
\hline
\end{tabular}

Prevalence and types of symptoms

Twelve point four percent $(\mathrm{N}=15)$ of all the respondents had symptoms associated with wearing latex gloves. The prevalence among radiology nurses, radiologists/residents, radiographers and darkroom technicians was $15 \%, 13.8 \%, 13.3 \%$ and $7.4 \%$ respectively (Table 3).

Table 3. Prevalence of latex reaction amongst diagnostic imaging health care personnel

\begin{tabular}{|l|l|l|l|}
\hline Occupation & $\begin{array}{l}\text { No } \\
\text { respondents }\end{array}$ & $\begin{array}{l}\text { No of symptomatic } \\
\text { respondents }\end{array}$ & $\begin{array}{l}\text { Prevalence } \\
(\%)\end{array}$ \\
\hline Radiologists/Residents & 29 & 4 & 13.8 \\
\hline Radiographers & 45 & 6 & 13.3 \\
\hline Radiology Nurses & 20 & 3 & 15.0 \\
\hline Darkroom Tech. & 27 & 2 & 7.4 \\
\hline Total & 121 & 15 & \\
\hline
\end{tabular}

Table 4. Symptoms associated with latex reactions reported by respondents

\begin{tabular}{|l|l|l|l|}
\hline Anatomical site & Symptom type & $\begin{array}{l}\text { No of } \\
\text { respondents }\end{array}$ & $\begin{array}{l}\text { Percentage } \\
\text { symptomatic } \\
\text { respondents }\end{array}$ \\
\hline Hands & Itching & 10 & 66.7 \\
\hline Hands & Redness & 11 & 73.3 \\
\hline Hands & Dry/cracked skin & 8 & 53.3 \\
\hline Hands & Burning sensation & 4 & 26.7 \\
\hline Hands & Scaling & 2 & 13.3 \\
\hline Hands & Swelling & 1 & 6.7 \\
\hline Hands & Eruptions & 1 & 6.7 \\
\hline Face & Eye irritation & 3 & 20.0 \\
\hline Upper respiratory tract & Sneezing & 1 & 6.7 \\
\hline Upper respiratory tract & Shortness of breath & 1 & 6.7 \\
\hline Upper respiratory tract & Coughing & 1 & 6.7 \\
\hline
\end{tabular}

One hundred percent $(\mathrm{n}=15)$ of symptomatic staff had problems with their hands whilst $20 \% \quad(n=3)$ had facial and respiratory symptoms each respectively. Of the symptomatic staff, $13.3 \%(\mathrm{n}=2)$ indicated that symptoms occurred on persistent basis; $53.3 \%$ $(n=8)$ suffered symptoms each time latex 
gloves were worn whilst $33.4 \%(\mathrm{n}=5)$ did not answer the question.

\section{Causal agents}

There was a history of atopy in $20 \%(n=5)$ of symptomatic individuals. Sixty percent $(n=9)$ of symptomatic individuals experienced symptoms using powdered latex gloves only; the remaining $40 \%(n=6)$ suffered symptoms when using both powdered and non-powdered latex gloves. A strong correlation $(\mathrm{r}=0.92)$ was shown between numbers of gloves worn per day and numbers of symptomatic individuals. Of all respondents who used 1 to 3, 4 to 5 and more than 5 pairs of gloves in an average working day, $8.4 \%(n=7), 18.5 \%(n=5)$ and $27.3 \%(\mathrm{n}=3)$, respectively were symptomatic (Table 5). Another correlation $(\mathrm{r}=0.87)$ was shown between length of time of wearing gloves and expression of symptoms. A prevalence of $11.1 \%(\mathrm{n}=10)$ and $16.1 \%(\mathrm{n}=$ 5) was noted in those using latex gloves for less than and more than an hour per day respectively (Table 5).

\section{Awareness of latex glove reaction}

About $62.8 \% \quad(\mathrm{n}=76)$ of all the respondents were aware of the problem of latex hypersensitivity prior to the questionnaire. Only $27.2 \%(n=45)$ of all respondents knew of at least one prevention strategy. Although $82.6 \%(\mathrm{n}=100)$ of the respondents were aware of using non-rubber latex gloves such as nitrile and vinyl as a means of prevention, few other strategies were known. Of the symptomatic respondents only $46.7 \%(n=7)$ were aware of prevention measures.

Tables 5. Relationship between symptoms and glove usage

\begin{tabular}{|l|l|l|l|}
\hline Glove Status & $\begin{array}{l}\text { Total number of } \\
\text { staff }\end{array}$ & $\begin{array}{l}\text { No of symptomatic } \\
\text { staff }\end{array}$ & Prevalence \\
\hline $\begin{array}{l}\text { 1) No of glove used } \\
\text { per day }\end{array}$ & & & \\
\hline i) $1-3$ & 83 & 7 & 8.4 \\
\hline ii) $4-5$ & 27 & 5 & 18.5 \\
\hline iii) $>5$ & 11 & 3 & 27.3 \\
\hline $\begin{array}{l}\text { 2) Duration of glove } \\
\text { use }\end{array}$ & & & \\
\hline$<1$ hour & 90 & 10 & 11.1 \\
\hline$>1$ hour & 31 & 5 & 16.1 \\
\hline
\end{tabular}

\section{Discussion}

The problem of hypersensitivity to natural rubber was first reported in 1979 [8]. Since then, there has been a steady increase in the number of new cases worldwide [9]. Previously, reactions to latex products such as gloves were believed to be caused only by the chemicals used in manufacturing and not by the latex rubber itself [10]. One study in Finland [11] reported that $2.9 \%$ of hospital personnel had documented latex reactions. Since then numerous studies have been conducted around the world.

Most studies have estimated that the prevalence of latex hypersensitivity in healthcare personnel ranges from $8 \%$ to $17 \%$ [10-13]. In a large cross-sectional study of 1351 hospital workers in Canada, a prevalence of $12.1 \%$ of latex hypersensitivity was identified. The prevalence was highest in laboratory workers $(16.9 \%)$ and nurses and physicians (14.33\%) [14]. Powdered gloves increase latex sensitization compared with the non-powdered variety [7]. Although the powder is not an allergen, it can attach to the latex protein residue and act as a hapten or carrier enhancing the allergic potential.

This paper presents the results of a preliminary study investigating the prevalence of symptoms associated with latex hypersensitivity amongst a small group of previously non- investigated Southeast Nigerian healthcare workers. Although the response rate of this study was high at $79 \%$, the numbers involved are small particularly for some sub-sections and therefore firm conclusions must be treated with an element of caution. The similarities of the findings in this present study to previous studies and the direct relationship demonstrated between expression of symptoms and time of exposure to latex 
gloves suggest that latex hypersensitivity amongst diagnostic imaging healthcare workers in Southeast Nigeria may be a real problem. Therefore, the need for further work on a larger scale is highlighted.

In this study, $12.4 \% \quad(n=15)$ of all respondents who used rubber latex gloves had symptoms previously associated with latex hypersensitivity. The prevalence amongst the sub-groups is $15 \%, 13.8 \%, 13.3 \%$ and $7.4 \%$ for radiology nurses, radiologists/residents, radiographers and darkroom technicians respectively. These rates are generally similar to those reported by previous authors [1013,15-17]. The aetiology of the symptoms presenting in this study is well described and most likely arise from Type I immediate hypersensitivity, Type IV delayed hypersensitivity (allergic contact dermatitis) and irritant contact dermatitis $[8,10]$.

The most frequent symptoms were redness and itching of the hands, which were reported by $73.3 \%$ and $66.7 \%$ of symptomatic individuals respectively. These results are similar to those found in previous studies $[15,18,19,21]$. Facial $(20 \%)$ and upper respiratory tract sneezing $(6.7 \%)$ shortness of breath $(6.7 \%)$ and coughing $(6.7 \%)$ symptoms in the present study are similar to the findings of Healy et al [15], but were reported to a greater extent here than in other studies $[14,18,20,21]$. This is most likely due to the previous works focusing on Type I hypersensitivity reactions, which do not include non-immunological mucosal irritation where powder is the offending irritant. In this study, most respondents indicated that they used powdered gloves frequently in the past, which may explain the frequency of facial and respiratory symptoms reported.

The strong association between symptoms and number of gloves and duration of exposure is strongly suggestive of a reaction to natural rubber latex gloves. Nurses and radiologists/residents reported the highest glove usage and had the highest prevalence of symptoms at $15 \%$ and $13.8 \%$ compared with $13.3 \%$ and $7.4 \%$ for radiographers and darkroom technicians respectively. These results are consistent with the findings of others [18,22-24]. Further work in our environment should focus on establishing exposure threshold for these symptoms.

About $62.8 \%(\mathrm{n}=76)$ of the respondents are aware that reaction to latex gloves could be a potential problem. This is an encouraging result. However, only $27.2 \% \quad(n=45)$ of respondents were aware of prevention strategies. Increased awareness of prevention of latex reaction is essential. Awareness and prevention strategies need to be put in place. Both employers and employees have specific responsibilities and these need to be emphasized by educational sessions, protocols and information sheets.

Notably in a self-reporting study of this nature, it should be acknowledged that subjects with symptoms might be more inclined to respond to a questionnaire than those without symptoms, which may lead to over estimation of the prevalence of reactions to the use of natural rubbers latex gloves. A further limitation was the dependency of this investigation on self-reporting of the symptoms and no clinical examinations or laboratory tests of symptomatic subjects were undertaken to conform or exclude reactions. Further work, therefore, should involve an interview based investigation to reduce any bias due to increased reporting by affected individuals in addition to physical measurements.

\section{Conclusion}

The present study has shown that symptoms highly suggestive of a reaction to wearing latex gloves are common in a population of diagnostic imaging hospital personnel in Nigeria. These results have provided a foundation for a further controlled study, which will address the stated limitations.

\section{References}

1. Murphy F. Latex hypersensitivity in the radiology department. Synergy. 1998; 00:10-11

2. Johnston G. Latex allergy: reducing the risk. New York Times. 1998; 9444: $60-70$

3. Duffield LD. Latex allergy: everyone's concern. Journal of the Michigan Dental Association. 1998; 80:30-8, 40, 42

4. Dyck RJ. Historical development of latex allergy. Association of Operating 
Room Nurses Journal. 2000; 72:27-9, 32-3, 35-40.

5. Potter P. Allergen of the decade. A publication of Allergy society of South Africa (ALLSA) 2006, Official website: www.allergysa.org

6. Miller KK. Research based prevention strategies: Management of Latex allergy in the workplace. American Association of Occupational Health Nurses Journal. 2000; 48: 278-290.

7. Potential for allergy to natural rubber latex gloves and other national rubber products $1999 . \quad$ Available: http://www.oshaslc.gov/html/hotfoias/ tib/TIB 1999 0412.html.

8. Nutter AF. Contact urticaria to rubber. British Journal of Dermatology. 1979; 101: 597-598.

9. American College of Allergy, Asthma and Immunology: Position Statement. Latex allergy, an emerging healthcare problem. Annals of Allergy, Asthma and Immunology .1995; 75: 19-21.

10. Roy DR. Latex glove allergy-dilemma for health care workers. An overview. American Association of Occupational Health Nurses Journal. 2000; 48: $267-$ 277.

11. Turjanmaa. K. Incidence of immediate allergy to latex gloves of hospital personnel. Contact Dermatitis. 1987; 17: 270-275.

12. Lagier F, Vervloet D, Lhermet I, Poyen D, Charpin D. Prevalence of latex allergy in operating room nurses. Journal of Allergy and Clinical Immunology. 1992; 90: 319-322.

13. Grzybowski M, Owen DR, Peyser PA, Johnson CC, Schork MA. The prevalence of anti-latex $1 \mathrm{gE}$ antibodies among registered nurses. Journal of Allergy and Clinical Immunology. 1996; 98:535-544.

14. Liss GM, Sussman GL, Deal K, Brown S, Cividino M, Siu S, Beezhold DH, Smith G, Swanson MC, Yunginger J, Douglas A, Holness DL, Lebert $\mathrm{P}$, Keith $\mathrm{P}$, Wasserman $\mathrm{S}$, Turjanmaa K. Latex allergy: epidermiological study of 1351 hospital workers. Occupational and Environmental Medicine. 1997; 54: 335-342.
15. Healy J, Brennan PC, Bowden JA. Latex glove sensitivity amongst diagnostic imaging healthcare personnel: a self-reporting investigation. Radiography. 2003; 9:23-27.

16. Kaczmarek RG, Silverman BG, Gross TP, Hamiton RG, Kessler E, Arrowsmith- Lowe JT, Moore RM Jr. Prevalence of latex specific $1 \mathrm{gE}$ antibodies in hospital personnel. Asthma and Immunology.1996; 76:5156.

17. Kibby T, Aki M. Prevalence of Latex sensitization in a hospital employee population. Asthma and Immunology.1997; 78:41-44.

18. Smedley J, Jury A, Bendall H, Frew A, Coggon D. Prevalence and risk factors for latex allergy: a crosssectional study in a United Kingdom hospital. Occupational and Environmental Medicine. 1999; 56:833-836.

19. Katelaris CH, Widmer RP, Lazarus RM. Prevalence of Latex allergy in a dental school. Medical Journal of Australia. 1996; 16:711-714.

20. Safadi GS, Corey EC, Taylor JS, Wagner WO, Pien LC, Metton Al Jr Latex hypersensitivity in emergency medical service providers. Annals of Allergy, Asthma and Immunology 1997; 77:39-42.

21. Sinha A, Harrison PV. Latex glove allergy among hospital employees: a study in the North-West of England. Occupational Medicine. 1998; 48:405410.

22. Kujala VM, Rejula KE. Gloveinduced dermal and respiratory symptoms among health care workers in one Finnish hospital. American Journal of Industrial Medicine 1995; 28:89-98.

23. Irish Legislation Guide to the Safety, Health and Welfare at Work Act, 1989 and the safety, Health and Welfare at Work (General Application) Regulations.1993; p78-96.

24. Lewis JV, Barry S, Mabs C. How does diagnosis of latex allergy affect people's lives? Journal of the American Academy of Dermatology. 2004; 50: s249. 